\title{
Two chemotypes of Penicillium crustosum based on the analysis of indolic components
}

\author{
Ken-ichi KaWaI*1, Koohei NozaWa*1, Tohru Yamaguchi*1, Shoichi NaKaJIMa*1, \\ and Shun-ichi UdAGAWA*2
}
河合賢一*1, 野沢幸平*1, 山口 亨*1, 仲嶋正一*1, 宇田川俊一*2：インドール 系代謝産物の分析を基礎とした Penicillium crustosum の二つの
ケモタイプについて

\begin{abstract}
Summary
From the investigation of the indole metabolites of six strains of Penicillium crustosum isolated from foods in Tokyo in 1983-1984, it was clear that the tested strains were divided into two chemotypes based on mycotoxin profile: chemotype I (the strains I-27, I-31, I-32) produced penitrems as main metabolites, whereas clavine alkaloids (fumigaclavine A, pyroclavine, and festuclavine) were obtained from chemotype II (the strains I-28, I-29, I-30). Roquefortine $\mathrm{C}$, cyclopenin, and viridicatin were the common components obtained from both chemotypes.
\end{abstract}

During the course of a survey on fungal contamination in retailed foods collected at the Shinagawa Ward Institute of Public Health Research, Tokyo in 1983-1984, six strains of Penicillium crustosum Thom were isolated from cocoa and bread. ${ }^{1)}$ We recently reported that penitrems were isolated as main components from one (strain I-31=NHL 6491) of these strains along with the new minor indoloditerpenes related to penitrems. ${ }^{2,3}$ We wish to report in this paper that penitrems were detected from the extract of two others (strains I-27 and I-32) by thin layer chromatography (TLC), whereas clavine alkaloids [fumigaclavine A (1), pyroclavine (2), and festuclavine (3)] were isolated from the remaining (strains I-28, I-29, and I-30). Roquefortine C, cyclopenin, and viridicatin were the common components obtained from all six strains.

\section{Materials and Methods}

Fungi The following six strains of Penicillium crustosum Thom obtained from the Shinagawa Ward Institute of Public Health Research (Tokyo) in 1983-1984 were used: the strains I-27, I-28, I-29, I-30, I-32 as isolates from retailed cocoa, and I-31 (=NHL 6491) as an isolate from bread for school lunch in Shinagawa-ku, Tokyo, respectively. From the colony characters on the standard media and the microscopical observations, ${ }^{4)}$ all strains were

*1 Faculty of Pharmaceutical Sciences, Hoshi University (Ebara 2-4-41, Shinagawa-ku, Tokyo 142). 星薬科大学薬学部 (下142 東京都品川区荏原2-4-41)

*2 Nodai Research Institute, Tokyo University of Agriculture (Sakuragaoka 1-1-1, Setagaya-ku, Tokyo 156).

東京農業大学総合研究所（干156 東京都世田谷区桜丘1-1-1） 
identified as $P$. crustosum, and there are no morphologically distinct differences among the strains.

For a comparison of mycotoxin-production profiles, the following representative cultures of $P$. crustosum and its closely related taxa were also used in this study: $P$. crustosum strain FRR 1809 (=ATCC 48911), P. commune Thom strains FRR 3112 and FRR 3169, and P. solitum Westling strains FRR 3174 and FRR 3249. These representative strains were obtained from the Division of Food Research, Ryde, New South Wales, Australia.

Cultivation conditions and extraction The fungus was cultivated at $25^{\circ} \mathrm{C}$ for 14 days on Czapek-Dox medium supplemented with $0.2 \%$ yeast extract in stationary condition containing $250 \mathrm{ml}$ of the above medium in each Roux flask. The harvested fresh mycelium was extracted with $\mathrm{CH}_{2} \mathrm{Cl}_{2}$, the solvent was evaporated, and the mycelial extract was obtained.

Analysis of $P$. crustosum metabolites by TLC The extract of the mycelium of each strain was developed on TLC plate (Merck Kieselgel $60 \mathrm{~F}_{254}$ ) using the solvent system of $\mathrm{CHCl}_{3}-\mathrm{Me}_{2} \mathrm{CO}(5: 1)$ or $\mathrm{CHCl}_{3}-\mathrm{MeOH}-27 \%$ aq. $\mathrm{NH}_{3}(90: 10: 1)$. Spots on TLC were detected by spraying van Urk's reagent. ${ }^{5)}$ Cyclopenin and viridicatin were detected by using UV absorption at $254 \mathrm{~nm}$.

Isolation of metabolites from $P$. crustosum, strain $I-28$ The mycelial extract $(4.2 \mathrm{~g})$, obtained from 120 Roux flasks, was chromatographed on silica gel with $\mathrm{C}_{6} \mathrm{H}_{6}-\mathrm{Me}_{2} \mathrm{CO}(3: 1)$ followed by repeated purification by low pressure liquid chromatography (LPLC) $\left[\mathrm{CHCl}_{3}-\right.$ $\mathrm{MeOH}-27 \%$ aq. $\left.\mathrm{NH}_{3}(190: 10: 1)\right]$ to obtain fumigaclavine $\mathrm{A}$ (1) $\left(310 \mathrm{mg}\right.$ ), and with $\mathrm{C}_{6} \mathrm{H}_{6}-$ $\mathrm{Me}_{2} \mathrm{CO}(1: 3)$ followed by purification by LPLC using the solvent system of $\mathrm{CHCl}_{3}-\mathrm{MeOH}-$ $27 \%$ aq. $\mathrm{NH}_{3}(190: 10: 1)$ to give pyroclavine (2) $(40 \mathrm{mg})$ and festuclavine (3) (3 mg).

Hydrolysis of fumigaclavine $A(1) \quad 1 N-\mathrm{NaOH}(2 \mathrm{ml})$ was added to the solution of fumigaclavine $\mathrm{A}(1)(30 \mathrm{mg})$ in $\mathrm{MeOH}(2 \mathrm{ml})$ and the mixture was refluxed for $2 \mathrm{hrs}$. After adding water, the reaction mixture was extracted with $\mathrm{CH}_{2} \mathrm{Cl}_{2}$ and dried over $\mathrm{Na}_{2} \mathrm{SO}_{2}$, and then the solvent was evaporated. The residue was purified by LPLC using $\mathrm{CHCl}_{3}-\mathrm{MeOH}-$ $27 \%$ aq. $\mathrm{NH}_{3}(190: 10: 1)$ to give fumigaclavine $\mathrm{B}(4)(24 \mathrm{mg})$.

\section{Results and Discussion}

TLC pattern of $P$. crustosum metabolites The results were indicated in Fig. 1. Cyclopenin and viridicatin were detected in all six strains by using UV absorption at $254 \mathrm{~nm}$. Production and confirmation of clavine alkaloids Three compounds (1, 2, and 3), which showed positive coloration (reddish purple) with van Urk's reagent, ${ }^{5)}$ were isolated from the mycelial extract of $P$. crustosum, the strain I-28. The molecular formula of 1 was determined as $\mathrm{C}_{18} \mathrm{H}_{22} \mathrm{~N}_{2} \mathrm{O}_{2}$ by high resolution mass spectrometry. The ${ }^{1} \mathrm{H}$-NMR spectrum of 1 (Table 1) was similar to that of roquefortine $A(5)$, one of the clavine alkaloids already isolated from $P$. roqueforti Thom $^{6)}$ and $P$. crustosum, ${ }^{7)}$ but the proton at C-7, observed at $\delta 5.66(1 \mathrm{H}, t, J=1.7 \mathrm{~Hz})$ in 1 , shifted to $\delta 5.16(1 \mathrm{H}, t, J=10 \mathrm{~Hz})$ in 5 . Therefore compound 1 was assumed as one of the stereoisomer of 5 , fumigaclavine $A$, originally isolated from Aspergillus fumigatus Fresenius. ${ }^{8)}$ In order to confirm the struc- 


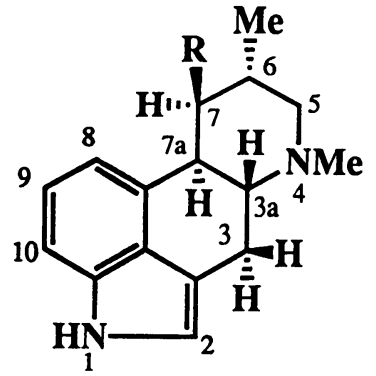

1: $\mathbf{R}=\mathbf{O A C}$

2: $\mathbf{R}=\mathbf{H}$

4: $\mathbf{R}=\mathbf{O H}$

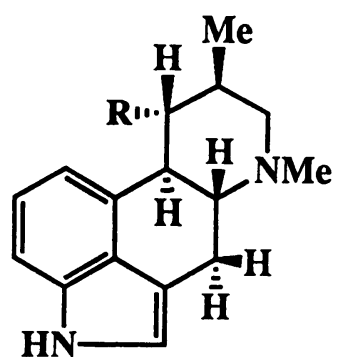

$$
\begin{array}{ll}
3: & \mathbf{R}=\mathbf{H} \\
\mathbf{5}: & \mathbf{R}=\mathbf{O A C}
\end{array}
$$

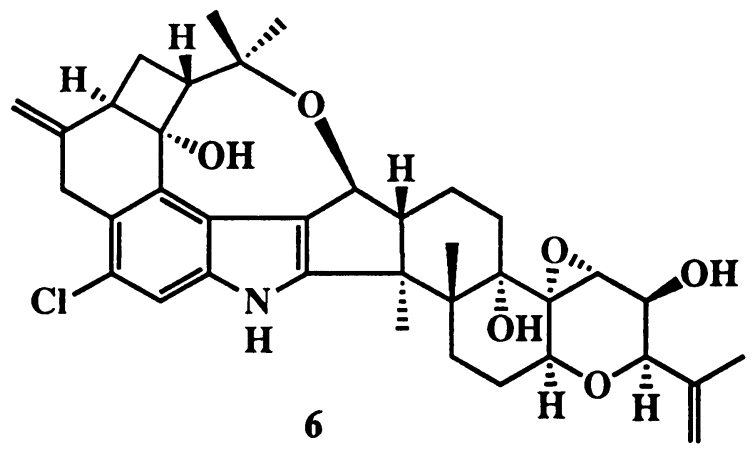

ture, 1 was hydrolysed with alkaline to give a deacetyl derivative (4). The spectral data of this compound was identical with those of fumigaclavine $\mathrm{B},{ }^{9)}$ including the optical rotation. The structure of compound 1 was consequently confirmed as fumigaclavine $\mathrm{A}$. Fumigaclavine B (4) was also detected in the extract of the above fungus by the analysis of TLC.

Both compounds 2 and 3 had the same molecular formula of $\mathrm{C}_{16} \mathrm{H}_{20} \mathrm{~N}_{2}$. The ${ }^{1} \mathrm{H}-\mathrm{NMR}$ spectra of 2 and 3 (Table 1) indicated clearly that they were two stereoisomers of the clavine alkaloids, i.e., pyroclavine, festuclavine, costaclavine, and epicostaclavine. ${ }^{10,11)}$ From the comparison of the ${ }^{1} \mathrm{H}-\mathrm{NMR}$ signals (Table 1$)^{11)}$ and the detailed decoupling experiments, the structures of compounds 2 and 3 were confirmed as pyroclavine and festuclavine, respectively.

Fumigaclavine $A(1)$ : Colorless needles, $\mathrm{mp}$ (dec.) $83-84^{\circ} \mathrm{C}$ (from aq. $\mathrm{MeOH}$ ). $[\alpha]_{\mathrm{D}^{20}}$ $-121^{\circ}$ ( $c=0.31$, pyridine). EI-MS $m / z: 298.1645\left(\mathrm{M}^{+}, 298.1680\right.$ for $\mathrm{C}_{18} \mathrm{H}_{22} \mathrm{~N}_{2} \mathrm{O}_{2}$ ), 239 (100). UV $\lambda_{\max }^{\mathrm{MeOH}} \mathrm{nm}(\log \varepsilon): 222$ (4.31), 275 (3.48), 281 (3.49), 292 (3.49). IR $\nu_{\max }^{\mathrm{KBr}} \mathrm{cm}^{-1}: 3400$, 3200 (NH), 1740 (OAc).

Pyroclavine (2): Colorless needles, $\mathrm{mp}$ (dec.) $205-208^{\circ} \mathrm{C}$ (from $\mathrm{C}_{6} \mathrm{H}_{14}-\mathrm{EtOH}$ ). $[\alpha]_{\mathrm{D}}{ }^{20}-94^{\circ}$ $\left(c=0.29\right.$, pyridine). EI-MS $m / z: 240.1624\left(\mathrm{M}^{+}, 240.1625\right.$ for $\left.\mathrm{C}_{16} \mathrm{H}_{20} \mathrm{~N}_{2}\right)$. UV $\lambda_{\max }^{\mathrm{MeOH}} \mathrm{nm}$ $(\log \varepsilon): 223$ (4.53), 275 (3.79), $281(3.81), 291$ (3.72). IR $\nu_{\max }^{\mathrm{KBr}} \mathrm{cm}^{-1}: 3100(\mathrm{NH})$. 

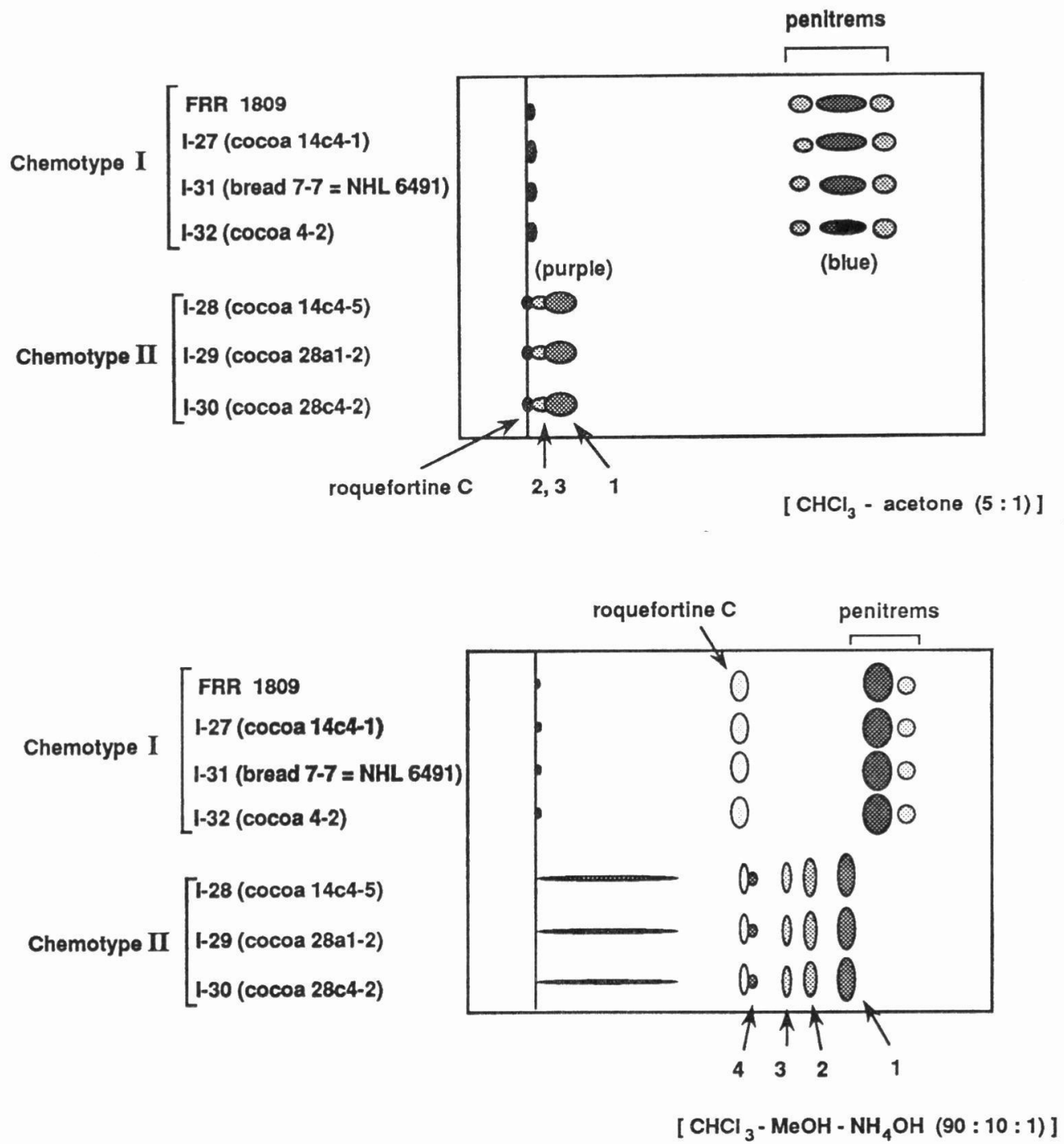

Fig. 1. TLC patterns of Penicillium crustosum.

응 van Urk's reagent $(+)$.

Festuclavine (3): Colorless crystalline powder. EI-MS $m / z$ : 240.1624 $\left(\mathrm{M}^{+}, 240.1625\right.$ for $\mathrm{C}_{16} \mathrm{H}_{20} \mathrm{~N}_{2}$ ).

Fumigaclavine $B(4)$ : Colorless needles, $\mathrm{mp}$ (dec.) $242-244^{\circ} \mathrm{C}$ (from hexane-EtOH). $[\alpha]_{\mathrm{D}}{ }^{20}$ $-94^{\circ}\left(c=0.30\right.$, pyridine). EI-MS $m / z: 256\left(\mathrm{M}^{+}, 72\right), 239(44), 154(100) . \quad \mathrm{UV} \lambda_{\max }^{\mathrm{MeOH}} \mathrm{nm}$ $(\log \varepsilon): 225$ (4.28), $275(3.77), 281$ (3.79), $292(3.68) . \quad \mathrm{IR} \nu_{\max }^{\mathrm{KBr}} \mathrm{cm}^{-1}: 3430(\mathrm{OH}), 3100$, $3050(\mathrm{NH})$.

Chemotypes of P. crustosum The result of the TLC patiern of the mycelial extracts of six strains of $P$. crustosum was shown in Fig. 1 . The first group, including strains I-27, I-31, and I-32, produces much of penitrems [main metabolite: penitrem A (6)], whereas 
Table 1. Proton chemical shifts of clavine alkaloids in $\mathrm{CDCl}_{3}[\delta(\mathrm{Hz})]$

\begin{tabular}{|c|c|c|c|c|}
\hline Proton & 1 & 2 & 3 & 4 \\
\hline $1-\mathrm{H}(\mathrm{NH})$ & $7.88 \mathrm{brs}$ & $7.88 \mathrm{brs}$ & 7.88 brs & 7.96 brs \\
\hline $2-\mathrm{H}$ & $6.87 \mathrm{~s}$ & $6.87 \mathrm{~s}$ & $\begin{array}{l}6.88 \mathrm{t} \\
(2)\end{array}$ & $6.88 \mathrm{~s}$ \\
\hline $3 \alpha-\mathrm{H}$ & $2.64 \mathrm{~m}$ & $\begin{array}{l}2.73 \text { ddd } \\
(15,11,2)\end{array}$ & $2.67 \mathrm{~m}$ & $\begin{array}{l}2.58 \mathrm{dd} \\
(13,12)\end{array}$ \\
\hline $3 \beta-H$ & $2.64 \mathrm{~m}$ & $\begin{array}{l}\text { 3. } 39 \text { dd } \\
(15,4)\end{array}$ & $\begin{array}{l}3.41 \mathrm{dd} \\
(15,4)\end{array}$ & $\begin{array}{l}3.29 \mathrm{dd} \\
(13,2)\end{array}$ \\
\hline $3 a-H$ & $2.64 \mathrm{~m}$ & $\begin{array}{l}2.08 \mathrm{ddd} \\
(11,10,4)\end{array}$ & $\begin{array}{l}2.13 \mathrm{td} \\
(10,4)\end{array}$ & $\begin{array}{l}2.66 \mathrm{td} \\
(12,2)\end{array}$ \\
\hline $4-\mathrm{Me}(\mathrm{NMe})$ & $2.43 \mathrm{~s}$ & $2.40 \mathrm{~s}$ & $2.47 \mathrm{~s}$ & $2.41 \mathrm{~s}$ \\
\hline $5 \alpha-\mathrm{H}$ & $\begin{array}{l}3.41 \mathrm{dd} \\
(12,3)\end{array}$ & $\begin{array}{l}2.77 \mathrm{dd} \\
(9,2)\end{array}$ & $2.67 \mathrm{~m}$ & $\begin{array}{l}3.38 \mathrm{dd} \\
(13,3)\end{array}$ \\
\hline $5 \beta-\mathrm{H}$ & $\begin{array}{l}2.71 \mathrm{dd} \\
(12,4)\end{array}$ & $2.43 \mathrm{~m}$ & $\begin{array}{l}1.89 \mathrm{t} \\
(11)\end{array}$ & $\begin{array}{l}2.82 \mathrm{dd} \\
(13,4)\end{array}$ \\
\hline $6-\mathrm{H}$ & $2.10 \mathrm{~m}$ & $2.11 \mathrm{~m}$ & $2.02 \mathrm{~m}$ & $2.13 \mathrm{~m}$ \\
\hline 6-Me & $\begin{array}{l}1.33 \mathrm{~d} \\
(7)\end{array}$ & $\begin{array}{l}1.29 \mathrm{~d} \\
(7)\end{array}$ & $\begin{array}{l}0.99 \mathrm{~d} \\
(6)\end{array}$ & $\begin{array}{l}1.28 \mathrm{~d} \\
(7)\end{array}$ \\
\hline $7 \alpha-\mathrm{H}$ & $\begin{array}{l}5.66 \mathrm{t} \\
(2)\end{array}$ & $2.42 \mathrm{~m}$ & $2.97 \mathrm{~m}$ & $4.53 \mathrm{brs}$ \\
\hline $7 \beta-\mathrm{H}$ & & $\begin{array}{l}1.69 \mathrm{td} \\
(13,5)\end{array}$ & $\begin{array}{l}1.09 \text { brq } \\
(12)\end{array}$ & \\
\hline 7-OAc & $1.88 \mathrm{~s}$ & & & \\
\hline $7-\mathrm{OH}$ & & & & $1.88 \mathrm{~s}$ \\
\hline $7 a-H$ & $\begin{array}{l}\text { 3. } 37 \text { brd } \\
\text { (9) }\end{array}$ & $\begin{array}{l}3,15 \text { ddd } \\
(13,10,4)\end{array}$ & $2.97 \mathrm{~m}$ & $\begin{array}{l}2.59 \mathrm{dd} \\
(12,5)\end{array}$ \\
\hline $8-\mathrm{H}$ & $\begin{array}{l}7.17 \mathrm{~d} \\
(8)\end{array}$ & $\begin{array}{l}7.16 \mathrm{~d} \\
(8)\end{array}$ & $\begin{array}{l}7.16 \mathrm{~d} \\
(8)\end{array}$ & $\begin{array}{l}7.20 \mathrm{~d} \\
(8)\end{array}$ \\
\hline $9-\mathrm{H}$ & $\begin{array}{l}7.11 \mathrm{t} \\
(8)\end{array}$ & $\begin{array}{l}7.14 \mathrm{t} \\
(8)\end{array}$ & $\begin{array}{l}7.15 \mathrm{t} \\
(8)\end{array}$ & $\begin{array}{l}7.19 \mathrm{t} \\
(8)\end{array}$ \\
\hline $10-\mathrm{H}$ & $\begin{array}{l}6.75 \text { brd } \\
\text { (8) }\end{array}$ & $\begin{array}{l}6.89 \mathrm{~d} \\
(8)\end{array}$ & $\begin{array}{l}6.93 \mathrm{dd} \\
(8,2)\end{array}$ & $\begin{array}{l}6.96 \mathrm{~d} \\
(8)\end{array}$ \\
\hline
\end{tabular}

Table 2. Mycotoxin production profiles of Penicillium crustosum and two closely related Penicillium species

\begin{tabular}{cclcccc}
\hline \multicolumn{2}{c}{ P. crustosum } & P. crustosum & \multicolumn{2}{c}{$P$. commune } & P. solitum $^{*}$ \\
Chemotype I & Chemotype II & & Chemotype I & Chemotype II & \\
\hline Penitrems A, & Fumigaclavines & Penitrems A, & Cyclopiazonic & Cyclopiazonic & Viridicatin \\
B, C, D, E, F & A, B & B-F & acid & acid & Viridicatol \\
Roquefortine C & Pyroclavine & Roquefortines & Cyclopiamine & Isofumigaclavine & Cyclopenin \\
Cyclopenin & Festuclavine & C, D & Ruglovasines & A & Cyclopenol \\
Viridicatin & Roquefortine C & Cyclopenin & A, B & Viridicatin & 3-O-Methyl- \\
& Cyclopenin & Cyclopenol & Isofumigaclavine Viridicatol & viridicatin \\
& Viridicatin & Viridicatin & A & Palitantin & Cyclopeptin \\
& & Viridicatol & Palitantin & Frequentin & Dehydrocyclo- \\
& & Viridicatic acid & Cyclopaldic acid & peptin \\
& & Terrestric acid & Cyclopolic acid & & Compactin \\
& & & Chromanol & & Dihydrocompactin \\
& & & & & ML 236A \\
& & & & & ML 236C \\
\hline
\end{tabular}

* Data by Frisvad and Filtenborg. ${ }^{12)}$ 
clavine alkaloids $(1,2$, and 3 ) were detected in the extract of the another group (I-28, I29 , and $\mathrm{I}-30$ ) in spite of no detection of penitrems. Roquefortine C, cyclopenin, and viridicatin were the common components obtained from all six strains.

Comparison of secondary metabolite profiles between our $P$. crustosum isolates and some representative strains of Penicillium spp. Frisvad and Filtenborg ${ }^{12)}$ recently reported that $P$. crustosum isolates constantly produce penitrem $\mathrm{A}(6)$, roquefortine $\mathrm{C}$, cyclopenin, viridicatin, and terrestric acid from the chemotaxonomical study (Table 2). From the similarity in the secondary metabolite profile, our isolates in the first group are assignable to the typical $P$. crustosum. In fact, the TLC pattern of $P$. crustosum, the representative strain FRR 1809, was superimposable to that of the first group.

In the production of clavine alkaloids and non-production of penitrems, the profile in the second group of our isolates was different from those of the strain FRR 1809 and the first group though they share the production of roquefortine $C$, cyclopenin and viridicatin. On the other hand, those of four strains of $P$. commune and $P$. solitum were entirely different from those of our isolates and the strain FRR 1809, as well as the data shown in Table 2. Therefore, it was clear that the second group of our isolates is much closer to $P$. crustosum than $P$. commune and $P$. solitum.

Thus we should proposed that $P$. crustosum is divided into two chemotypes: chemotype I (the representative strains FRR 1809, I-27, I-31, and I-32) produces a lots of penitrems, and roquefortine $C$, cyclopenin, and viridicatin; chemotype II (the strains I-28, I-29, and I-30) produces clavine alkaloids, i.e., fumigaclavine A (1), pyroclavine (2), and festuclavine (3) instead of penitrems as the indole derivatives in the former.

\section{References}

1) Yamaguchi, T., Nozawa, K., Nakajima, S., Kawai, K., Udagawa, S.: Proc. Jpn. Assoc. Mycotoxicol., 34, 29 (1991).

2) Hosoe, T., Nozawa, K., Udagawa, S., Nakajima, S., Kawai, K.: Chem. Pharm. Bull., 38, 3473 (1990).

3) Yamaguchi, T., Nozawa, K., Hosoe, T., Nakajima, S., Kawai, K.: Phytochemistry, accepted.

4) Pitt, J. I.: "The Genus Penicillium and Its Teleomorphic States Eupenicillium and Talaromyces," p. 1-634 (1979), Academic Press, London.

5) Stahl, E., Kaldeway, H.: Hoppe-Zeiler's Z. Physiol. Chem., 323, 182 (1961).

6) Ohmomo, S., Sato, T., Utagawa, T., Abe, M.: Agric. Biol. Chem., 39, 1333 (1975).

7) Cole, R. J., Dorner, J. W., Cox, R. H., Raymond, L. W.: J. Agric. Food Chem., 31, 655 (1983).

8) Spilsbury, J. F., Wilkinson, S.: J. Chem. Soc., 2085 (1961).

9) Cole, R. J., Kirksey, J. W., Dorner, J. W., Wilson, D. M., Johnson, J., Jr., Johnson, N., Bedell, D., Springer, J. P., Chexal, K. K., Clardy, J., Cox, R. H.: J. Agric. Food Chem., 25, 655 (1977).

10) Bach, N. J., Boaz, H. E., Kornfeld, E. C., Chang, C. J., Floss, H. G., Hagaman, E. W., Wenkert, E.: J. Org. Chem., 39, 1272 (1974).

11) Ninomiya, I., Kiguchi, T.: J. Chem. Soc., Chem. Commun., 624 (1976).

12) Frisvad, J. C., Filtenborg, O.: Mycologia, 81, 837 (1989). 